\title{
The effect of asymmetric stimulation on the apparent median plane
}

JOHN B. REID

UNIVERSITY OF OREGON

An experiment was conducted to determine the effects of an asymmetrical, distractor stimulus placed at varied distances from the objective median plane on the amount of shift of the apparent median plane. A non-monotonic relationship was found between degree of asymmetry and amount of shift. Although all degrees of asymmetry effected a shift in apparent median plane, the largest shift occurred when the distractor stimulus was asymmetrical by 40 degrees.

The apparent median plane (A.M.P.) may be defined as that position in space which is judged to be straight ahead. Werner \& Wapner (1952) have found that when Ss are instructed to report the point at which the edge of a luminous rectangle is directly to their front, in a darkened room, the $A_{0}$ M. P. is displaced toward the middle of the rectangle; $i_{0} e$. , if they located the left edge, the A.M.P. shifted to the right, and vice versa. The authors interpreted this result as a case of "symmetrization," since the Ss' A.M.P. shifted in such a way that the visual stimulation was made more nearly symmetrical. The present investigation was conducted to study the effects on the A.M.P. of different degrees of asymmetry of visual stimulation in a darkened room. The use of a movable, cylindrical stimulus which could be placed at various angular distances from the objective median plane (the objectively measured straight ahead) made it possible to determine the functional relationship between degree of asymmetry and amount of shift of the A. M, P.

\section{Subjects}

Eighteen college sophomore students, naive as to the purpose of the study, participated as subjects in the experiment.

\section{Apparatus}

A. Target Light. A small box with a rectangular $2-1 / 2$ in. $x 2$ in. opaque glass front, containing a $7-1 / 2$ volt, $110 \mathrm{~A} . \mathrm{C}$. light bulb, was mounted on wheels in such a manner that $\mathrm{E}$ could roll it along the $4 \mathrm{in}$. surface of a straight track which was $6 \mathrm{ft}$. in length. To the box was attached a pointer which allowed the location of the center of the rectangular light on the track to the nearest $1 / 4$ in. The track was calibrated in $1 / 4$ in. from 0 on the left to 280 on the right.

B. Chair and Headrest. Eight ft. in front of the track a standard classroom desk chair was situated. A headrest was attached to the arm of the chair in such a way that it was directly in front of $S$. Since $S$ had to lean forward to place his head in the rest, the track, described above, was placed on a table (30 in. high) so that the rectangular light would be approximately at S's eye level. The center of the track was directly to the front of the seated $\mathrm{S}$.

C. Asymmetric Stimulus. A vertically oriented oblong box with a rectangular 11-1/2 in. $x 1$ in. opaque glass front, containing a $7-1 / 2$ volt, $110 \mathrm{~A} . \mathrm{C}$. light bulb, was movable to any point in a circular arc with a radius of $8 \mathrm{ft}$. and a height of $30 \mathrm{in}$. around the chair. The position on the arc at which this vertical light was placed determined the degree and the direction of asymmetry of the visual field. The 10 positions chosen were $30,40,50,60$ and 70 degrees to each side of the objective front of the chair.

The experiment was conducted in a dark room. Method

Ss were tested one at a time. $S$ was told to close his eyes and was then led by $E$ into the experimental room and seated in the chair. The room was then darkened and the test lights were switched on. $S$ was then told to open his eyes. The instructions were as follows: "Do you see the small rectangle and the cylinder of light?" All Ss answered in the affirmative. "I am going to move the small rectangle and I want you to tell me when the middle of the light is directly in front of you. Do you have any questions? I want you to close and open your eyes whenever I ask you to. Okay." All Ss seemed to understand the procedure, as they had no questions.

Each trial consisted of the following: The asymmetric stimulus was placed at one of the 10 angular positions, the target light was moved to either the far right or far left of the track, S was instructed to open his eyes, the target light was then moved slowly along the track until $S$ reported that it was directly to his front, and finally $S$ was instructed to close his eyes and the location of the target was recorded.

Each S made 40 judgments of the A.M.P., four with the asymmetric stimulus at each of the 10 positions (two judgments with the target light starting from the right and two judgments with it starting from the left of the track). S's eyes remained closed between trials while the cylinder and the target light were relocated. Each $\mathrm{S}$ was given a different order of presentations so that effects of practice, fatigue, and starting position of the target light would be counterbalanced.

\section{Results}

In order to ascertain the effects of varying degrees of asymmetric stimulation, the responses given when the vertical stimulus was on the left were subtracted from those given when it was on the right, for each angular position of the distractor. A mean difference 
score was computed for each of the five angular positions of the distractor $(30,40,50,60$ and 70 degrees) for each $\mathrm{S}$. The larger the mean difference, the larger the shift of the apparent median plane. Figure 1 shows the average shift of A.M.P. for all Ss as a function of angular distance of the distractor. It can be seen that in all positions the asymmetric stimulus effected a shift in the A.M.P. The direction in each case was toward the side of asymmetric stimulation.

An analysis of variance showed that the differences

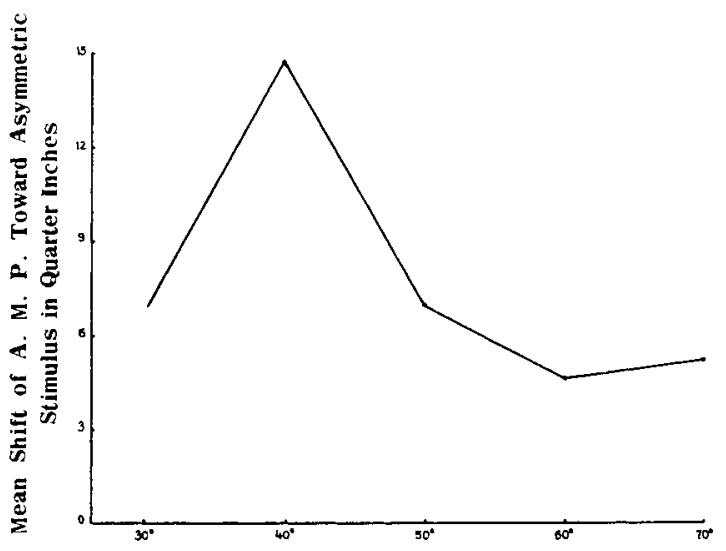

Angular displacement of distractor stimulus from Objective Median Plane

Fig. 1. Mean shift of A. M. P. as a function of degree of asymmetry. in amount of shift between different positions of the distractor were greater than could be expected by chance $(F=6.21, d f=4 / 68, p=.01)$. Almost all of the variance between distractor positions was accounted for by position No. 2 (SS =1131.56), which was significantly more effective than the other four positions $(p<.001)$. Discussion

The finding that all degrees of asymmetry studied in the present investigation caused a compensating shift, or symmetrization, of the S'S A.M.P. is in agreement with the findings of Werner \& Wapner (1952). The shifts were always in the direction of the asymmetrical stimulus.

Figure 1 shows that the amount of shift is not monotonically related to the degree of asymmetry. The largest shift took place when the distractor light was asymmetrical by 40 degrees. It seems likely that the shift of the A.M.P. becomes greater the more asymmetrical the total visual stimulation is made, up to a point (about 50 degrees) at which the asymmetric stimulus is no longer perceived in direct relation to the target light. At that point the resultant shift is lessened.

\section{Reference}

Werner, H., \& Wapner, S. Toward a general theory of perception. Psychol. Rev., 1952, 59, 324-338. 